\title{
ANĀLISE POPULACIONAL DE COLÔNIAS DE POLYBIA (MYRAPETRA) PAULISTA (IHERING, 1896) (HYMENOPTERA, VESPIDAE)
}

VERA LÍGIA LETÍZIO MACHADO •

\begin{abstract}
The data suggest that Polybia (Myrapetra) paulista colonies are established by means of swarm formation having the existence of an initial polygyny and a pleometrose being proved. The reproductive forms are produced once a year (at the start of the year); however, the colonies can last for two or three years. The observations evidenced that the duration of a development period is about 100 days.
\end{abstract}

\section{INTRODUÇÃO}

Polybia (Myrapetra) paulista é uma espécie comuníssima no Brasil, especialmente no Estado de São Paulo, ocorrendo também nos Estados de Goiás, Mato Grosso, Paraná e Minas Gerais, com registro no Paraguai e Argentina.

Os ninhos fragmocítaros caliptódomos desta espécie possuem forma cônica e globosa, com um único orifício de comunicação com o exterior, um pouco acima da última camada. A presente espécie foi denominada sucessivamente Polybia scutellaris var. paulista H. von Ihering, 1896; Polybia occidentalis var. scutellaris forma paulista Ducke, 1910, e atualmente, segundo Richards (1978), Polybia (Myrapetra) paulista H. von Ihering. Segundo Thering (1896) a variedade paulista pouco difere da P. scutellaris, ambas são inteiramente pretas com o escutelo intensamente amarelo, distinguindo-se apenas pela maneira especial de construirem os ninhos, constituindo pois, variações biológicas. Ducke (1910), entretanto, afirma que ocorrem transições na cor e na estrutura do ninho. Bruch (1936) mostrou que ninhos novos de P. o. scutellaris são lisos como os de $P$. paulista, mas adquirirem espinhos no segundo ano, quando a colônia cresce.

Muita coisa tem sido realizada com Polybia paulista no que se refere à distribuição geográfica (Ducke, 1910; Richards, 1978) descrições de ninhos (Ihering, 1904; Ducke, 1907; Brèthes, 1902; Bertoni, 1911; Richards \& Richards, 1951), taxonomia (Bequaert, 1944; Cameron,

* Departamento de Zoologia, Instituto de Biociências, Campus de Rio Claro, UNESP. 
1912; Ducke, 1910; Richards, 1978) e desenvolvimento larval (Carvalho \& Teles da Silva, 1975) mas resta ainda toda a dinâmica da organização para se investigar.

Bruch (1936) observou uma colônia de $P$. o. scutellaris por 4 anos consecutivos e Rodrigues (1968) estudou melhor a sua organização social. Muitas outras contribuições têm sido realizadas com objetivo de elucidar a biologia das vespas sociais neotropicais; entretanto, estudos básicos de análise populacional em diferentes fases de desenvolvimento, duração do ciclo e a sazonalidade das colônias só mais recentemente foram citados em Machado (1974, 1977 a e b), Rodrigues (1968, 1971, 1981 a e b), Raposo Filho (1981) e Silva (1981).

Desta maneira, os objetivos do presente trabalho foram os seguintes: determinar a composição dos enxames e de colônias em diferentes fases de desenvolvimento, existência de haplo ou pleometrose, época de produção das operárias e das formas reprodutivas, duração do ciclo da colônia e a sazonalidade destas.

\section{MATERIAL E MÉTODOS}

As colônias analisadas foram coletadas na região de Rio Claro, SP (22॰25'S, 47॰32'WGr) e Piracicaba, SP (22042'S, 47॰30'WGr) e localizadas especificamente em beirais de construções, árvores, plantas herbáceas, janelas, etc., com preferência por lugares com pelo menos uma face livre para o vôo. A determinação de todas colônias foi baseada nas descrições de Bequaert (1944), Ducke (1910), Richards (1978) e pela comparação dos exemplares com o material identificado pelo Professor Owain Westmacoit Richards na University of London.

O procedimento para a captura e conservação das colônias em laboratório foi o mesmo indicado por Richards \& Richards (1951) e Rodrigues (1968) para Polistini e Polybiini.

Antes e após a captura, são tomadas algumas fotografias; a captura dá-se à noite, salvo em dias de chuva, quando se processa a qualquer hora, pois os habitantes encontram-se recolhidos. Assim, com o mínimo de luz incidente e com auxílio de fumigador, coloca-se o saco plástico em torno do ninho, fechando-o em seguida ao seu redor, despregando-se do suporte de fixação.

As colônias levadas ao laboratório são anestesiadas com gás carbônico ou éter e fixadas em solução Dietrich. Para melhor fixação dos adultos, estes são colocados em um dessecador ligado a uma bomba de vácuo por 10-15 minutos, a fim de retirar todo o ar do material.

Após permanecer no fixador por 24 horas, o material é lavado em álcool $50 \%$ por 24 horas e depois conservado em álcool $70 \%$.

O procedimento no laboratório com o ninho, cria e adulto, foi o mesmo estabelecido por Machado (1977) para Protopolybia pumila. Os favos são retirados, contados e, após a determinação de suas áreas, é estimado o número total de células do ninho. A idade da colônia (periodos de desenvolvimento) é estimada segundo método descrito em Richards \& Richards (1951). A cria é retirada das células, separada e 
contada. Os adultos são contados e dissecados em sua totalidade e os machos separados, a olho nu, por apresentarem diferenças morfológicas.

Os dados obtidos pela dissecação observam desenvolvimento do ovário, padronizado em 5 tipos: $\mathrm{ND}=$ fêmeas com ovários filamentosos; ID = fêmeas apresentando um início de desenvolvimento (1 a 4 óvulos); $\mathrm{D}=$ com ovários desenvolvidos (5 a 8 óvulos); $\mathrm{BD}=\mathrm{com}$ ovários desenvolvidos (9 a 12 óvulos) e $\mathrm{MD}=$ com ovários muito desenvolvidos, possuindo mais de 13 óvulos; situação da espermateca: vazia (V) ou cheia (C); conteúdo do intestino, desenvolvimento do corpo gorduroso, presença de parasitas, etc.

Os ovários ND são encontrados nas operárias, enquanto que ID, D e $B D$ nas intermediárias, uma vez que a espermateca esteja vazia, segundo classificação de Pardi (1940, 1947) e Richards \& Richards (1951), e MD nas rainhas, desde que a espermateca esteja cheia de esperma.

\section{APRESENTAÇÃO E DISCUSSÃO DOS RESULTADOS}

Procurou-se registrar e analisar colônias em diferentes estágios de desenvolvimento usando-se uma metodologia essencial para o estudo de populações, ou seja, o levantamento de dados a fim de se permitir uma análise quantitativa e o aprofundamento em alguns aspectos de sua organização.

Para um estudo de dinâmica populacional é necessário considerar a estruturação social que é cíclica e portanto, o entendimento da espécie será tentado através do estudo das colônias coletadas e observadas de 1974 a 1982.

A primeira colônia, H-8, de aproximadamente 40 dias, foi coletada em 12.01.74, na cidade de Rio Claro, especificamente em um canto do forro de uma varanda residencial, a 3,0 metros do solo.

O ninho H-8 apresentou a forma mais ou menos globular, com $25 \mathrm{~cm}$ de diâmetro e uma abertura central para o exterior, localizada em uma porção projetada, em elevação.

Utilizando-se os métodos e técnicas já descritos, os favos separados e enumerados a partir do mais recente, mostraram o seu conteúdo:

Favo I: mel

Favo II: ovos e larvas pequenas mais centralmente e pouco mel nos bordos.

Favo III: na mesma situação do favo anterior.

Favo IV: larvas médias no centro, ovos e larvas menores mais para a periferia, mel nos bordos.

Favo V: pouco mel.

A idade estimada para a presente colônia foi de 0,6 períodos; portanto, uma população enxameante. A análise da colônia revelou a 
presença de 478 rainhas com ovaríolos D (maioria) e BD (somente três) e espermateca cheia, para o total de 1770 indivíduos. Presume-se que tenha ocorrido uma situação similar à encontrada para Protopolybia mumila (Machado, 1977) e $P$. exigua exigua (Machado, 1974) onde, por falta de condições para a sobrevivência, as intermediárias (rainhas em potencial) foram fecundadas. Nesta colônia encontrou-se 20 fêmeas parasitadas por Strepsiptera (Xenidae: Brasixenos s.). A presença do parasita nas fêmeas de $P$. paulista foi notada pela observação de hérnias pretas e brilhantes que faziam saliência nas membranas intersegmentares. Essas hérnias eram constituídas pelo cefalotórax das larvas ou adultos, sempre orientados com a cabeça voltada para a região posterior do hospedeiro e a face esternal para o lado externo, isto é, o parasita ocupa o lado dorsal ou ventral do abdome do hospedeiro, preferencialmente entre o $5^{\circ}$ e $6^{\circ}$ tergitos.

As vespas parasitadas por Brasixenos apresentaram regressão ovariana, situação chamada estilopização, estudada por Strambi (1965a, 1965b, 1966, 1967). Outros dados de análise de conteúdo da colônia H-8 constam da tabela I e figura 1 .

A colônia H-10 foi coletada em 23.03.76 na cidade de Rio Claro, no forro da área de uma casa a 2,80 metros do solo. Segundo as informações dos proprietários da casa, a idade da colônia foi de aproximadamente 100 dias.

O ninho apresentou a forma aproximadamente globular, com $20 \mathrm{~cm}$ de diâmetro, uma abertura para o exterior localizada numa porção projetada em elevação e 4 favos, cujos conteúdos são mostrados:

Favo I: só mel.

Favo II: mel nos bordos, ovos e larvas no centro.

Favo III: algumas pupas no centro, ovos e larvas ao redor.

Favo IV: na mesma situação do favo anterior.

Encontrou-se nesta colônia inicial rainhas D e BD, além da presença de intermediárias e operárias. Esta colônia apresentou 11 fêmeas parasitadas por Strepsiptera (Brasixenos $\mathrm{sp}$ ). Através da cria da colônia H-10 estimou-se uma idade de 0,8 a 1 período de desenvolvimento.

Outros dados da análise do conteúdo da colônia constam da tabela I e figura 2 .

A colônia H-11 foi coletada em 12.04.76 no beiral do Departamento de Geografia da Faculdade de Filosofia, Ciências e Letras de Rio Claro, a 3 metros do solo, e com 35 dias de permanência no local (população enxameante). 
O ninho, como é peculiar à espécie, apresentou a forma globular, com $19 \mathrm{~cm}$ de diâmetro, uma única abertura para o exterior e 4 favos que mostraram o seguinte:

\author{
Favo I: vazio. \\ Favo II: mel e ovos. \\ Favo III: ovos e larvas pequenas mais centralmente e pouco mel \\ nos bordos.
}

Favo IV: ovos e larvas.

Foram encontradas duas fêmeas com tecido adiposo muito desenvolvido; além disso a colônia apresentou-se com rainhas $\mathrm{D}$ e BD, poucas intermediárias e muitas operárias, que compunham o enxame. Outros dados da colônia constam da tabela I e figura 3 .

A. colônia H-16 foi localizada em Rio Claro, nas proximidades do Departamento de Educação da Faculdade de Filosofia, Ciências e Letras de Rio Claro, em 13.11.76, em um galho de arbusto a 2,30 metros do solo. A idade calculada foi de 1,6 períodos, deduzido através da cria presente.

O ninho H-16 apresentou a forma mais ou menos globular, com $22 \mathrm{~cm}$ de diâmetro, uma única abertura para o exterior e 5 favos cujos conteúdos são mostrados:

Favo I: só mel.

Favo II: mel nos bordos e ovos dispostos mais centralmente.

Favo III: ovos e larvas pequenas mais centralmente reocupando células, alguns casulos ao redor e pouco mel nos bordos.

Favo IV: muitas pupas no centro, ovos e larvas ao redor.

Favo V: na mesma situação do favo anterior.

Nesta colônia, os dados revelaram uma colônia em fase fêmea produtora com rainhas $\mathrm{D}$ e $\mathrm{BD}$; portanto, com poucos óvulos em seus ovários, devido, provavelmente, às oviposições já efetuadas. A colônia apresentou também 5 fêmeas parasitadas por Strepsiptera (Xenidae Brasixenos sp) e em 23 fêmeas foram encontradas na cavidade abdominal massas esféricas esbranquiçadas. Apenas uma fêmea apresentou-se simultaneamente com Strepsiptera e massas esféricas esbranquiçadas, que até o momento não foram identificadas. Outros dados da colônia constam da tabela I e figura 4.

A colônia H-18 foi coletada em 19.02.77, na cidade de Rio Claro, no forro de uma casa, mais ou menos a 3 metros do solo. Segundo as informações, esta colônia encontrava-se aproximadamente a 1 ano no local. 
O ninho apresentou a forma mais ou menos globosa, com $27 \mathrm{~cm}$ de diâmetro e uma abertura para o exterior localizada numa porção projetada em elevação. Os 8 favos que compunham o ninho mostraram:

Favo I: (único) um pouco do mel no centro e de um lado.

Favo II: (único) ovos e larvas pequenas no centro e mel na periferia.

Favo III: (único) poucas pupas no centro rodeadas de ovos e pequenas larvas em células reocupadas e pouco mel nas células periféricas.

Favo IV: (único, mas apresentando 2 favos unidos) os ovos centralmente dispostos reocupam as células, ao redor poucas pupas, larvas pequenas e mel nos bordos.

Favo V: (dois favos distintos $\mathrm{Va}$ e $\mathrm{Vb}$ ), Va = larvas maiores no centro, ovos e larvas pequenas mais para a periferia em células contendo restos fecais e pouco mel nos bordos. $\mathrm{Vb}=$ poucas pupas, ovos e larvas pequenos mais centralmente reocupando células e mel nos bordos.

Favo VI: (dois favos VIa e VIb), VIa = ovos e larvas em células reocupadas, mel nos bordos. VIb $=$ larva e pupas no centro, larvas pequenas e ovos ao redor, reocupando células e uma fileira do mel nos bordos.

Favo VII: ( 2 favos VIIa e VIIb), VIIa = células vazias contendo apenas 3 camadas de restos fecais, algumas células com mel nos bordos. VIIb = larvas grandes no centro, ovos e larvas pequenas ao redor em células reocupadas e poucas células nos bordos com mel.

Favo VIII: favo de inserção vazio.

Aparentemente, pela divisão inicial dos favos, a colônia H-18 seria resultado de duas colônias coligadas.

As construções dos favos (nos envelopes anteriores) formam lateralmente uma porção de trabéculas com um aspecto externo rugoso assemelhando-se a um telhado.

A colônia H-18 apresentou machos e fêmeas, indicando uma fase reprodutiva. Os machos aparecem sempre antes da enxameação; entretanto, pela presença de somente 7 machos e 26 rainhas, pode-se concluir que a colônia tenha já emitido vários enxames. Em colônias grandes de muitos Polybiini (Richards \& Richards, 1951) os ciclos são calculados em um ano, ou em vários anos. Bruch (1936) observou 
uma colônia de Polybia occidentalis scutellaris intermitentemente, por 4 anos, mas esta espécie pode atingir até 30 anos (Rodrigues, 1968). No caso em estudo, evidenciou-se que os machos são produzidos uma vez por ano, podendo a colônia emitir vários enxames, mas o ciclo de desenvolvimento geralmente continua, sendo observadas colônias com 2 a 3 anos de existência.

Os adultos da colônia H-18 apresentaram-se intensamente parasitados por Strepsiptera (Xenidae - Brasixenos $\mathrm{sp}$ ) sendo que foram encontradas muitas fêmeas contendo mais de um parasita em seus abdômens (2, 3, até 4 por abdômens). Separando-se os 754 parasitas encontrados, observou-se a presença de 90 fêmeas, 387 machos (1o :4,3 ł ) e 297 larvas. Os machos destes Strepsiptera encontravam-se em estágio de pré-pupa e pupa, e vários deles já apresentavam asas; portanto, tratava-se de machos eclodidos mas não emergidos do hospedeiro.

Outros dados desta colônia constam da tabela I e figura 5 .

A colônia H-20 foi coletada em 07.07.77, na cidade de Rio Claro, no forro de uma casa a 3 metros do solo. Esta colônia foi acompanhada desde o início e coletada para análise após 200 dias de sua fundação.

O ninho apresentou a forma globular, com $16 \mathrm{~cm}$ de diâmetro, 2 aberturas para o exterior, estando uma delas (a inferior) em comunicação com o favo I. Os 7 favos foram separados e mostraram o seguinte conteúdo:

Favo I: vazio.

Favo II: células com restos fecais e pouco mel em algumas células limpas.

Favo III: mel nos bordos, células com restos fecais no centro e material de estocagem (térmitas e formigas).

Favo IV: poucos ovos no centro em células reocupadas, mel nos bordos e material de estocagem consistindo principalmente de abdômens de térmitas.

Favo V: poucos ovos e larvas reocupando células, mel nos bordos.

Favo VI: idem ao favo anterior.

Favo VII: (favo de inserção): mel nos bordos, alguns ovos em células reocupadas pela segunda vez.

A colônia H-20 apresentou-se com uma população fraca, de somente 230 indivíduos, compreendendo 29 rainhas, 3 machos e 198 operárias, indicando portanto uma fase reprodutiva.

Fato interessante foi também observar o parasitismo de dois machos por Strepsiptera. Os machos, como já foi relatado anteriormente, são produzidos uma vez por ano, geralmente no final deste, quando 
então se encontram vários enxames reprodutivos. Entretanto, é estranho estar ocorrendo machos nesta época do ano (julho) em colônias de aproximadamente 6,5 meses. Isto parece justificar-se, talvez, pela inatividade destes machos, provocada pelo parasitismo (controle sazonal?).

Outros dados da colônia constam da tabela I e figura 6 .

A colônia G-50 foi coletada em 13.12.76 na cidade de Piracicaba, no beiral do Departamento de Entomologia (ESALQ-USP, Piracicaba) a 2,80 metros do solo. Segundo o seu histórico, a colônia encontrava-se aproximadamente há 1 ano no local.

O ninho apresentou a forma típica globosa, com $24 \mathrm{~cm}$ de diâmetro, uma abertura para o exterior e os favos cujos conteúdos são mostrados:

Favo I: só mel.

Favo II: mel nos bordos em células limpas, ovos centralmente dispostos, reocupando células.

Favo III: mel nos favos e mais para o centro algumas pupas (maioria machos), ovos e larvas reocupando células.

Favo IV: idem ao favo anterior.

Favo V: ovos e larvas no centro, algumas pupas esparsas, todos em células contendo restos fecais, pouco mel nos bordos.

Favo VI: situação similar ao favo anterior, células reocupadas pela 3a. vez.

Favo VII: poucas larvas grandes e pupas ao centro, células vazias ao redor e mel nos bordos.

Favo VIII: idem ao favo anterior.

Favo IX: poucas larvas e uma só pupa em células contendo restos fecais, mel nos bordos.

Favo $\mathrm{X}$ : pouco mel em células já usadas.

A colônia G-50 apresentou-se em uma fase finalíssima do desenvolvimento (fase reprodutiva) onde muitos machos estavam presentes (337), mas um número muito reduzido de rainhas foi constatado através das dissecções. A olho nu foram separadas 294 possíveis rainhas (pelo aspecto de seus grandes abdômens e coloração mais amarronzada) das quais, após as dissecções, revelaram ser apenas 18 com seus ovários muito desenvolvidos e espermateca cheia. As fêmeas restantes (276) encontravam-se intensamente parasitadas por Strepsiptera (Xenidae - Brasixenos sp.) contendo cada uma delas de 1 a 6 parasitas por abdômens. Da mesma maneira, somente 101 machos eram funcionais, pois grande parte destes $(236=70 \%)$ estavam parasitados, contendo de 1 a 4 Strepsiptera por abdômen. Separando-se os 512 parasitas 
encontrados, observou-se a presença de 209 fêmeas e 301 machos de Brasixenos sp. com um «sex-ratio» de 1 o : 1,4 f̂, além de 93 larvas.

Acredita-se que grande parte das rainhas tenham sido parasitadas e sofrido o fenômeno de estilopização, uma vez que a desproporção sexual encontrada nessa colônia de vespa foi de 1 우 : 5,6

Outros dados da colônia G-50 constam da tabela I e figura 7 .

A colônia G-51 foi coletada em 03.01.77 no beiral do Departamento de Entomologia (ESALQ - USP, Piracicaba) a 3,50 metros do solo. O ninho apresentou a forma globular, com $16 \mathrm{~cm}$ de diâmetro, com uma abertura para o exterior e composto de 7 favos cujo conteúdo mostrou:

Favos I, II: mel nos bordos.

Favo III: poucas pupas no centro ao redor, algumas larvas e ovos, mel nos bordos.

Favo IV: muitas pupas ao centro, larvas e ovos ao redor, mel nos bordos.

Favo V: ovos e larvas ao centro reocupando células, ao redor pupas prontas a eclodir juntamente com larvas pequenas e médias e mel nos bordos.

Favo VI: ovos e larvas ao centro e pupas ao redor.

Favo VII: (inserção): só mel.

Através deste conteúdo pode-se estimar uma idade de 1,4 períodos. E de estranhar a presença de 2 machos em uma colônia fêmea-produtora, c que leva a pensar na existência de colônia reprodutiva nas proximidades, uma vez que já é fato conhecido, tanto para abelhas como para vespas, que os machos podem visitar várias colônias sem ser molestados.

Coincidindo com estes dados, duas colônias reprodutivas foram observadas próximas, a uns 50 metros da colônia em questão. Das 892 operárias, somente 20 estavam parasitadas por um Strepsiptera, Brasixenos sp., contendo uma única 2 parasitas do sexo feminino. Outros dados da colônia constam da tabela I e figura 8 .

A colônia G-52, em fase reprodutiva, foi coletada em 20.02.78, em Piracicaba, a 5 metros do solo, presa ao teto de um prédio, próximo a uma lâmpada de neon. O ninho apresentou-se com a forma mais ou menos globosa, de $28 \mathrm{~cm}$ de diâmetro e uma abertura para o exterior localizada numa porção projetada em elevação. Foi o maior ninho (analisado) tanto em número de favos como no número estimado de células, mas com poucos habitantes, o que parece demonstrar que vários enxames já tinham sido emitidos. Os treze favos que compunham o ninho mostraram os seguintes conteúdos: 
Favo I: vazio

Favo II: pouco mel.

Favo III: poucos ovos e larvas pequenas dispostos centro-lateralmente, mel nos bordos.

Favo IV: idem ao favo anterior.

Favo V: mais centralmente, ovos e larvas pequenas em células contendo restos fecais e mais lateralmente dispostos, ovos e larvas em células ocupadas pela primeira vez; mel nos bordos.

Favo VI: pupas dispostas mais centralmente, ovos e larvas ao seu redor reocupando células, mel nos bordos.

Favos VII

e VIII: na mesma situação do favo VI, somente com um número maior de pupas.

Favo IX: larvas reocupando células e pouco mel nos bordos.

Favo $\mathrm{X}$ : desprovido de cria, somente células vazias contendo os restos fecais deixados pelo menos por 3 gerações, algumas células com mel.

Favos XI,

XII e XIII: idem ao favo anterior.

A população adulta era composta por machos, fêmeas férteis fecundadas ou não e fêmeas estéreis (operárias). Dessas fêmeas férteis foram encontradas 37 rainhas fecundadas (contendo em média 22 óvulos em seus ovários) e 3 «rainhas jovens» ou intermediárias com ovários potencialmente desenvolvidos (contendo de 9 a 13 óvulos nos ovários) e espermateca vazia. Isto vem evidenciar uma fase reprodutiva onde machos e fêmeas férteis são produzidos.

Observou-se também nesta colônia um intenso parasitismo (12,8\% da população) por Brasixenos sp. (Strepsiptera), comumente encontrado.

Os machos presentes estavam em sua totalidade (4) parasitados, contendo em seus abdômens de 1 a 4 parasitas; já as 108 fêmeas parasitadas continham em seus abdômens 1 a 5 parasitas. Dos 112 Brasixenos separados observou-se a presença de 62 fêmeas e 84 machos (1 ㅇ: 1,3 ô) e 39 larvas. Outros dados da colônia G-52 constam da tabela I e figura 9.

Pela análise da disposição da cria nos favos das colônias estudadas, verificou-se que as posturas ocorrem geralmente do centro para a periferia. Houve, também, constância nas colônias quanto ao número de favos. Em colônias iniciais observou-se ninhos de 4 a 5 favos, constituídos rapidamente e, somente quando a população aumenta, novos favos são adicionados, podendo-se encontrar até 15, em colônias maiores. 
Outras colônias ainda coletadas ou observadas durante esse período de nove anos não foram analisadas, pois foram destinadas a outros experimentos; entretanto, contribuíram para a determinação da época da emissão dos enxames reprodutivos e da duração do ciclo da colônia.

Conhecendo-se a idade dos enxames de várias colônias coletadas foi estımada a duração do período de desenvolvimento (ovo - imago) em torno de 100 dias, sendo os machos e rainhas jovens produzidos no terceiro período.

Assim, as evidências indicaram que os enxames reprodutivos ocorrem de fato nos meses chuvosos de fim e início de ano, quando são produzidos os machos e fêmeas férteis. As operárias, por sua vez, são produzidas nos periodos intermediários. Uma colônia desta espécie pode permanecer no local até 2 a 3 anos, mas enxames periódicos são emitidos, geralmente uma vez ao ano.

O desenvolvimento inicial das colônias de $P$. paulista dependem de um grupo composto por várias fêmeas férteis fecundadas (rainhas) acompanhadas por centenas de fêmeas estéreis (operárias) e às vezes algumas fêmeas não fertilizadas (intermediárias) com ovário potencialmente desenvolvidos, porém não se registrou a presença de machos nestes enxames.

As análises das várias colônias coletadas em diferentes estágios de desenvolvimento revelaram a existência de uma poliginia inicial e uma pleometrose permanente nas colônias de Polybia paulista. Entretanto, verificou-se uma variação grande quanto ao número de indivíduos presentes nas colônias (230-2709) e mesmo a proporção das castas existentes nas diferentes fases de desenvolvimento não foi constante, como observado em Protopolybia pumila (Machado, 1977).

\section{CONCLUSŌES}

As evidências demonstraram que as colônias de $P$. paulista são fundadas através de enxameações, observando-se a existência de uma poliginia inicial e uma pleometrose permanente. As formas reprodutivas são produzidas uma vez ao ano (final ou começo de ano); entretanto, as colônias podem permanecer no local por 2 ou 3 anos.

A duração do período de desenvolvimento estimado foi de aproximadamente 100 dias.

\section{REFERENCIAS}

BEQUAERT, J. C., 1944. The social Vespidae of the Guianas, particulary of British Guiana. Bull. Mus. comp. Zool. 94 (7): 249-304.

BERTONI, A. de W., 1911. Contribución à la biologia de las avispas y abejas del Paraguay. An. Mus. nac. Buenos Aires 22 : 97-146.

BRÉTHES, J., 1902. Sur quelques nids de Vespides. Ibid. 1: 413-418.

BRUCH, C., 1936. Notas sobre el "Camuati" y las avispas que lo construyen. 
COMERON, P., 1912. The Hymenoptera of the Georgetown Museum. Part III. The marabuntas or wasps. J. Agric. Soc. British Guiana 2 (3): 207-231.

CARVALHO, G.G. \& TELES DA SILVA, M., 1975. Alguns aspectos do desenvolvimento larval de Polybia paulista Richards (Hymenoptera - Vespidae). Studia Ent. 18 (1/4): 555-568.

DUCKE, A., 1907. Novas contribuições para o conhecimento das vespas (Vespidae sociales) da região neotropical. Bol. Mus. Goeldi 5: 152-199.

DUCKE, A., 1910. Révision des guêpes sociales polygames d’Amerique, Ann. Mus. nat. Hung. 8: 449-544.

IHERING, H. von, 1896. L'état des guêpes sociales du Brésil. Bull. Soc. zool. France 21: 159-162.

IHERING, R. von, 1904. As vespas sociais do Brasil. Rev. Mus, paulista 6: 9-309.

MACHADO, V.L.L., 1974. Aspectos biológicos de Protopolybia exigua exigua (Saussure, 1854) (Hym. - Vespidae). Tese de Doutoramento, ESALQ - USP. Piracicaba. Brasil, $105 \mathrm{pp}$.

MACHADO, V.L.L., 1977. Aspectos da biologia de Protopolybia pumila (Saussure., 1863) (Hym. - Vespidae). Revta bras. Biol. 37 (4): 771-784.

PARDI, L., 1940. Ricerche sui Polistini. I. Poliginia vera ed apparente in Polistes gallicus (L.) P.V. Soc. Nat. 49: 3-9.

PARDI, L., 1947. Beobachtungen über das interindividuelle Verhalten bei Polistes gallicus. Untersuchungen über die Polistinae no 10. Behaioiour 1: 138-172.

RAPOSO FILHO, J.R., 1981. Biologia de Mischocyttarus (Monocyttarus) extinctus Zikán, 1935 (Polistinae - Vespidae). Dissertação de Mestrado. Instituto de Biociências. UNESP. Rio Claro, SP., Brasil, 163 pp.

RICHARDS, O.W., 1978. The social wasps of the Americas (excluding the Vespinae). British Museum (Natural History) London, $571 \mathrm{pp}$.

RICHARDS, O.W. \& RICHARDS, M.J., 1951. Observations on the social wasps of South America (Hym. - Vespidae). Trans. r. ent. Soc. Lond. 102: 1-170.

RODRIGUES, V.M., 1968. Estudos sobre vespas sociais do Brasil (Hym. Vespidae). Tese de Doutoramento, F.F.C.L. de Rio Claro, SP., Brasil, 113 pp.

RODRIGUES, V.M., 1971. Notas preliminares sobre o comportamento de Protopolybia pumila (Saussure, 1963) (Hym. - Vespidae). Revta Agri. Piracicaba $46(2 / 3): 117-120$.

RODRIGUES, V.M. \& MORAES, R.A.O., 1981. Vespídeos Sociais: estudo de Polybia (Apopolybia) jurinei de Saussure, 1854 (Polistinae - Polybiini). An. Soc. ent. Brasil 10 (1): 3-7.

RODRIGUES. V.M.; SANTOS, B.B.; LUCCA, C.A.T. \& ALMEIDA, M., 1981 Vespídeos sociais: estudos de colônias de Polybia (Trichothorax) chrysothorax (Lichtenstein) (Hymenoptera, Vespidae, Polistinae, Polybiini). Revta bras. Ent. 25 (2) : 149-153.

SILVA, M.N., 1981. Ciclo de desenvolvimento das colônias de Mischocyttarus (Kappa) atramentarius Zikàn, 1949 (Hym. - Vespidae). Fase de Pré-emergência Dissertação de Mestrado. Instituto de Biociências, UNESP, Rio Claro, SP., Brasil, 200 pp.

STRAMBI, A., 1965. Dynamique de la fonction ovarienne les Polistes (Hym. - Vesp.) Cas de l'ouvrère. C.R. Acad. Sc. Paris 260: 4599-4601.

STRAMBI, A., 1965b. Influence du parasite Xenos vesparum Rossi (Strepsiptères - Stylopides) sur les cellules neurosécrétion des individus du sexe femelle de Polistes gallicus L. (Hym. - Vespidae). Ibid. 260: 3768-3769.

STRAMBI, A., 1966. Action de Xenos vesparum Rossi (Strepsitère) sur la neurosécrétion des fondatrices filles de Polistes gallicus L. (Hym. - Vespidae) em diapause. Ibid. 26.3: 533-535.

STRAMBI, A., 1967. Effects de la disparition du parasite Xenos (Insectes Strepsiptères) sur la neurosécrétion protocérebrale de son hôte Polistes (Hym. - Vespides). Ibid. 264: 2646-2648. 


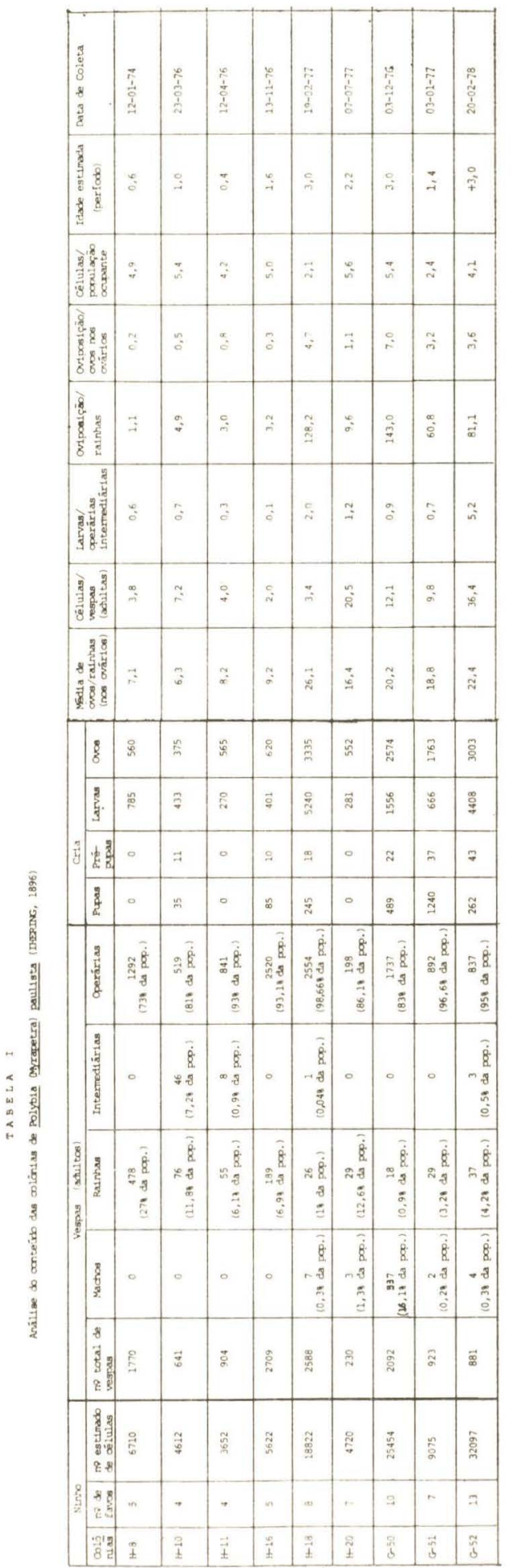


Revta bras. Zool.

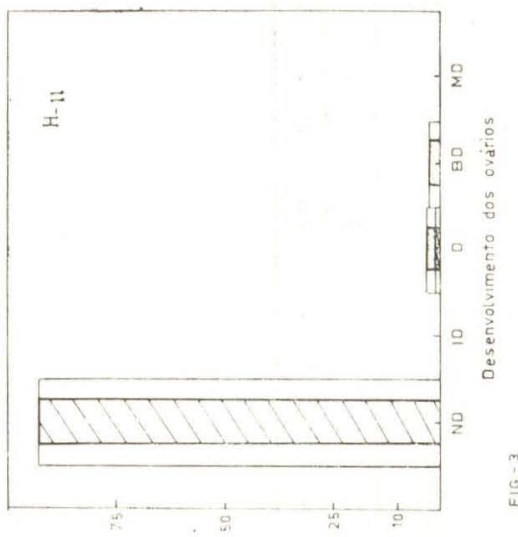

opseindod ep o. wa piauanbajy
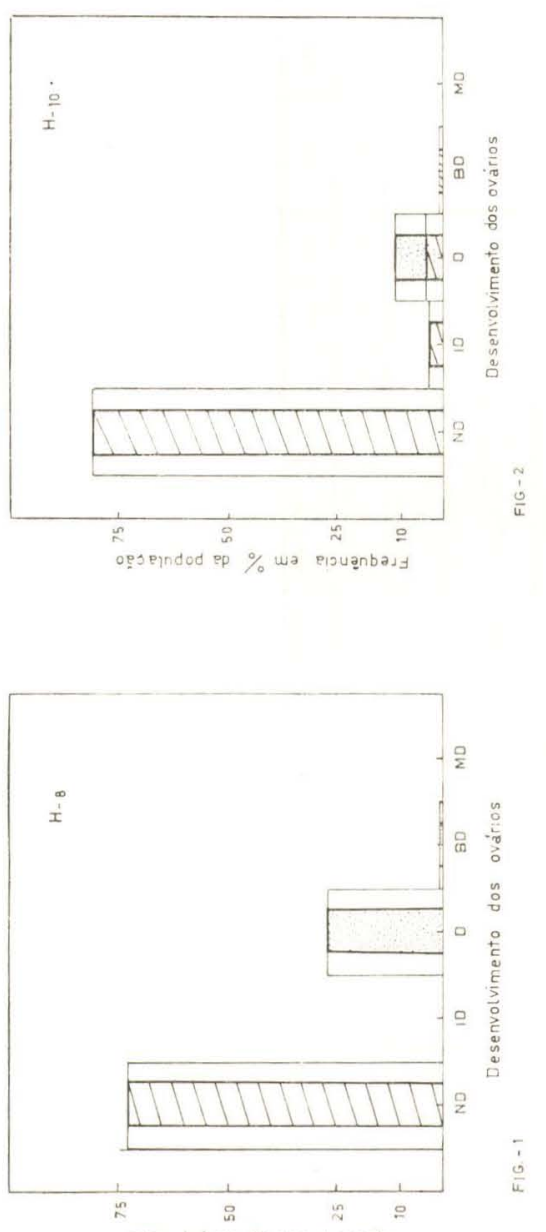
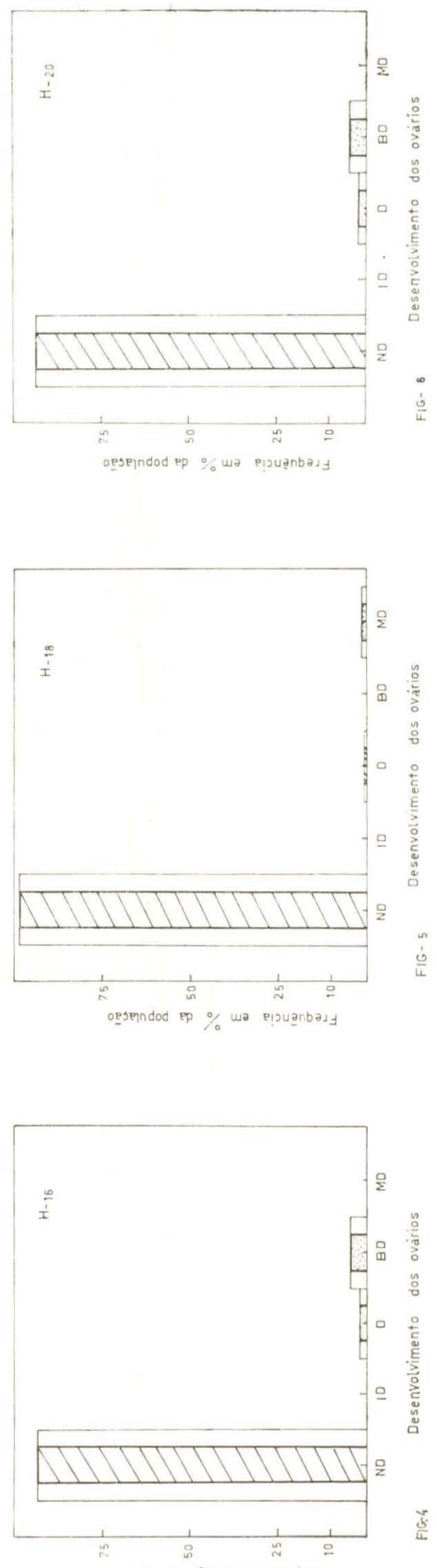


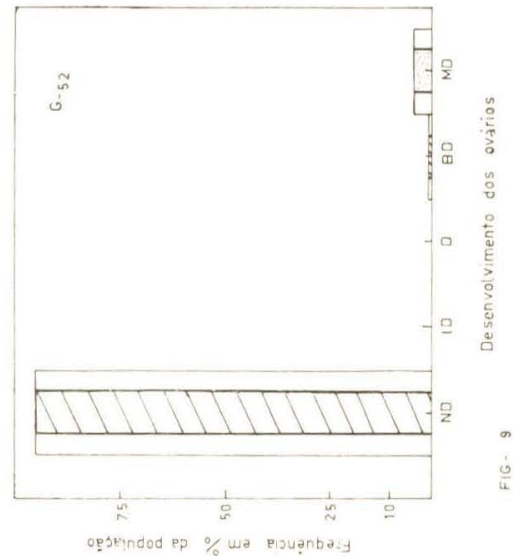

oparindod ep \% wa eizuanbaly

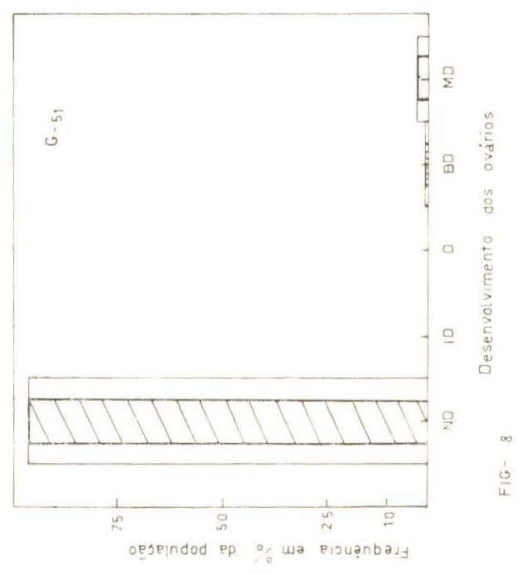

